common between micro-organisms and human tissues are possible elements in autoimmunity.

\section{THU0094 EXPERIMENTAL MYCOPLASMA FERMENTANS INFECTION IN RHEUMATOID SYNOVIAL FIBROBLASTS INDUCES M161AG EXPRESSION}

${ }^{1} \mathrm{~S}$ Kitajima, ${ }^{1} \mathrm{M}$ Kawano, ${ }^{1} \mathrm{H}$ Mutoh, ${ }^{1} \mathrm{I}$ Koni, ${ }^{1} \mathrm{H}$ Mabuchi, ${ }^{2} \mathrm{M}$ Matsumoto, ${ }^{2} \mathrm{~T}$ Seya. ${ }^{1}$ Second Department of Internal Medicine, Kanazawa University, Kanazawa; ${ }^{2}$ Department of Immunology, Osaka Medical Center for Cancer and Cardiovascular Diseases, Osaka, Japan

\subsection{6/annrheumdis-2001.971}

Background Mycoplasma fermentans (Mf) is one of the most likely of the several infectious agents which may be involved in the pathogenesis of rheumatoid arthritis (RA). Mf has been shown to induce arthritis experimentally in rabbits, and several reports have succeeded in detecting it in synovial fluids in RA patients. M161Ag is a $43-\mathrm{kDa}$ surface lipoprotein of Mf, which induces cytokine production in monocytes and activates the host complement system.

Objectives The aim of this study was to investigate whether M161Ag can be induced on rheumatoid synovial fibroblasts by an Mf infected cell line in vitro.

Methods Rheumatoid synovial cells were isolated from synovial tissue specimens obtained at operation. Production of $\mathrm{Mf}$ infected rheumatoid synovial cells was performed using a coculture system of synovial cells and P39 (+) cells, which were Mf containing human leukaemia cell lines, for three days. PCR with mycoplasma specific primers were done to detect Mf DNA in synovial cells. M161Ag expression was evaluated by an immunohistochemical method with MK5 and MK53 monoclonal anti M161Ag antibodies, and mRNA production was also evaluated by the RT-PCR method.

Results Freshly isolated rheumatoid synovial cells were negative for Mf DNA using PCR with mycoplasma specific primers. DNA of Mf ribosomal RNA was detected in the synovial fibroblasts after coculture of synovial cells and P39 (+) cells by PCR with mycoplasma specific primers. Moreover, the expression of M161Ag was detected only on Mf infected synovial cells using the immunohistochemichal method with MK5 or MK53 monoclonal antibodies.

Conclusion Experimental in vitro Mf infection in rheumatoid synovial fibroblasts was demonstrated to induce the expression of M161Ag. The significance of this finding requires clarification in further studies.

\section{REFERENCES}

1 Matsumoto $M$, et al. A novel protein that participates in nonself discrimination of malignant cells by homologous complement. Nat Med. 1997;3:1266

2 Matsumoto $M$, et al. Structural and functional properties of complement-activating protein M161Ag, a Mycoplasma fermentans gene product that induces cytokine production by human monocytes. J Biol Chem. 1998;273:12407

\section{THU0095 CIRCULATING AND LOCAL SYNOVIAL FLUID RENIN- ANGIOTENSIN SYSTEM IN PATIENTS WITH RHEUMATOID ARTHRITIS AND OSTEOARTHRITIS}

${ }^{1} V$ Çobankara, ' $\mathrm{M}$ Çalgüneri, ${ }^{1} \mathrm{~S}$ Apras, ${ }^{1} \mathrm{~S}$ Kiraz, ${ }^{1}$ I Ertenli, ${ }^{1}$ I Haznedaroglu, ${ }^{1} \mathrm{MA}$ Oztürk, ${ }^{2} \mathrm{O}$ Portakal, ${ }^{3} \mathrm{Z}$ Koray. ${ }^{1}$ Rheumatology; ${ }^{2}$ Biochemistry; ${ }^{3}$ Nuclear Medicine, Hacettepe University School of Medicine, Ankara, Turkey
Background Recent researches demonstrated presence of local RAS in myocardium, ovary and brain. Angiotensin converting enzyme (ACE) was shown to be produced by synovial membrane macrophages. Angiotensin II is a potent vasoconstrictor, and also can stimulate angiogenesis, fibroblast proliferation and growth factor expression. Hypertrophy and hyperplasia of synovium and angiogenesis are well documented in persistant rheumatoid synovitis.

Objectives In this cross-sectional study we aimed to detect ACE and renin levels in serum and synovial fluid (SF) of patients with RA and osteoarthritis OA.

Methods Sixteen patients with RA (13F, 3M), 13 patients with $\mathrm{OA}(8 \mathrm{~F}, 5 \mathrm{M})$ and 11 healthy controls (HC) (5F, 6M) were enrolled in the study. The commercially available AngiotensinConverting Enzyme kit and ACE calibrator were used. Renin assay was carried out with a two-site immunoreactive assay.

Results Median serum ACE levels were $48 \mathrm{U} / 1,45 \mathrm{U} / \mathrm{l}$, and 33 $\mathrm{U} / \mathrm{l}$ in RA patients, OA patients, and HC, respectively. Median serum renin levels were $12.9 \mathrm{pg} / \mathrm{ml}, 11.8 \mathrm{pg} / \mathrm{ml}$, and $17.9 \mathrm{pg} / \mathrm{ml}$ in RA patients and OA patients, respectively. Neither of these results were statistically significant $(p>0.05)$. SF levels of ACE and renin were found to be increased in RA patients ( $44 \mathrm{U} / \mathrm{l}$ and $3.5 \mathrm{pg} / \mathrm{ml}$ ) compared to $\mathrm{OA}$ patients (24 U/1 and $1.2 \mathrm{pg} / \mathrm{ml}$ ) (Table 1). Synovial fluid renin levels in patients with RA was negatively correlated with disease duration.

\begin{tabular}{llll} 
Abstract THU0095 Table 1 & & \\
\hline & RA & OA & HControls \\
\hline No of patients & 16 & 13 & 11 \\
Serum ACE (U/I) & $48(15-103)$ & $45(10-82)$ & $33(30-84)$ \\
Serum renin (pg/ml) & $12.9(1.2-67)$ & $11.8(1.6-39.2)$ & $17.9(17.9-36.6)$ \\
SF ACE (U/l) & $44(14-133)$ & $24(9-103)$ & \\
SF renin (pg/ml) & $3.5(0.48-15)$ & $1.2(0.5-4)$ & \\
\hline
\end{tabular}

Conclusion In this study we demonstrated that ACE and renin levels were elevated in SF of RA patients while serum ACE and renin levels were comparable to those in OA patients and healthy controls. These observations suggest presence of local RAS in RA synovium. Since angiotensin have stimulatory roles in angiogenesis and fibroblast proliferation, local RAS may participate in pannus formation and joint destruction in patients with RA. Negative correlation of synovial renin with disease duration may be compatible with previous observations that joint erosion is most prominent during the first months of the disease. Further studies, including mRNA of ACE and angiotensin II are needed to clarify exact roles of RAS in the pathogenesis of RA.

\section{THU0096 EFFECT OF ANAKINRA (IL-1RA) AND SOLUBLE TUMOUR NECROSIS FACTOR RECEPTOR I (STNF-RI) ON CELLULAR IMMUNE FUNCTION IN RATS}

${ }^{1} \mathrm{JE}$ Atkinson, ${ }^{2} \mathrm{RV}$ House, ${ }^{1} \mathrm{PS}$ Cranmer, ${ }^{1} \mathrm{AE}$ Colucil, ${ }^{1} \mathrm{H}$ Davis, ${ }^{3} \mathrm{CK}$ Edwards, ${ }^{4} \mathrm{DM}$ Miller. ${ }^{1}$ Toxicology; ${ }^{2}$ Toxicology, Covance, Madison, USA; ${ }^{3}$ Inflammation Research; ${ }^{4}$ Development, Amgen, Thousand Oaks

\subsection{6/annrheumdis-2001.973}

\section{Background}

Objectives This study investigated the potential for combined treatment with inhibitors of IL-1 and TNF- $\alpha$ to affect 
immunocompetence by assessing function of selected cell types involved in host resistance.

Methods Basal NK cell activity, lymphoproliferation following stimulation with anti-CD3, pokeweedmitogen or concanavalin A, and antibody forming cell response (AFC) were determined in splenocytes from female rats $(\mathrm{F}-344 ; \mathrm{N}=12$ per group) treated with placebo, IL-1ra alone (20 or $200 \mathrm{mg} / \mathrm{kg}$, SC daily), sTNF$\mathrm{RI}$ alone $(5$ or $50 \mathrm{mg} / \mathrm{kg}$, SC twice weekly) or the dose combinations of the two cytokine inhibitors for 21 days. Satellite groups received positive control agents for the NK cell assay $(0.5 \mathrm{~mL}$ anti-asialo GM 1 antibody) or the mitogenesis and AFC assay (25 mg/kg cyclophosphamide).

Results Basal NK cell response was increased 21\% ( $\mathrm{p}<0.05$ ) over placebo control only at the combination of $200 \mathrm{mg} / \mathrm{kg}$ IL$1 \mathrm{ra}+5 \mathrm{mg} / \mathrm{kg}$ sTNF-RI. No effect was noted with IL-1ra or TNF-RI alone or at higher combination doses. Cells from IL-1ra $(200 \mathrm{mg} / \mathrm{kg})$ treated animals showed minimal decreases $(30 \%, \mathrm{p}$ $<0.05)$ on lymphocyte proliferation only in response to anti CD3-mediated proliferation. Statistically significant differences $(+10$ to $-48 \%)$ in proliferative activity to all mitogens were observed with sTNF-RI alone or in combination with IL1-ra, but were not dose related. Diminution in the AFC response (29$36 \%)$ was noted for sTNF-RI alone $(50 \mathrm{mg} / \mathrm{kg})$ or in combination with both Il-1ra doses compared to the control group; however the differences were not statistically significant. IL1-ra alone, the low dose of sTNF-RI $(5 \mathrm{mg} / \mathrm{kg}$ ) alone or in combination with IL-1ra doses had no significant effect on AFC response.

Conclusion Thus, IL-1ra alone has minimal effects on selected functions of the immune system. Effects on immune function noted at $50 \mathrm{mg} / \mathrm{kg}$ sTNF-RI were considered minimal and importantly were not exacerbated by the combination of IL-1ra.

\section{THU0097 THE DISCREPANCY BETWEEN MRNA AND PROTEIN EXPRESSION OF THE TUMOUR-SUPPRESSOR GENE MASPIN IN SYNOVIAL TISSUE MIGHT CONTRIBUTE TO SYNOVIAL HYPERPLASIA IN RHEUMATOID ARTHRITIS (RA)}

1J Schedel, 'E Jeisy Walder, ${ }^{2}$ B Simmen, ${ }^{1}$ BA Michel, 'RE Gay, 'S Gay. 'Center of Experimental Rheumatology, Department of Rheumatology, University Hospital of Zurich; ${ }^{2}$ Department of Orthopedic Surgery, Schulthess Clinics, Zurich, Switzerland

10.1136/annrheumdis-2001.974

Background RA is a chronic disease characterised by tumour-like features such as synovial hyperplasia, invasive growth of the synovium and joint destruction. Maspin is a member of the serpin family of protease inhibitors with gene sequence similarities to plasminogen activator inhibitor. Maspin exhibits also tumoursuppressor activity by inhibiting cell motility, invasion and metastasis, and is down-regulated in breast and prostate cancer.

Objectives We investigated the expression of maspin in RA synovial tissue and compared it with the expression in osteoarthritis (OA) and normal synovial tissues (NS).

Methods The expression of maspin was determined in synovial tissue samples obtained during synovectomy or arthroplastic surgery. Using specific primers for maspin, a $237 \mathrm{bp}$ fragment was amplified from cDNA obtained from cultured RA (6), OA (4) and normal (1) synovial fibroblasts (SF) by reverse transcription polymerase chain reaction (RT-PCR). In addition, mRNA expression levels were determined quantitatively by real-time PCR (TaqMan). Using non-radioactive in situ hybridization, mRNA expression of maspin was investigated using snap-frozen and paraffin sections. To identify the cell types expressing maspin, immunohistochemistry was performed on serial tissue sections using monoclonal antibodies against CD3 (T cells) and CD68 (macrophages). SDS-PAGE and Western blotting was performed using anti-maspin antibodies to evaluate the protein expression in total synovial tissue and in cultured synovial fibroblasts (3rd 4th passage). Protein from normal breast tissue was used as positive control.

Results RT-PCR revealed expression of maspin in all cDNA samples from cultured synovial fibroblasts. By real-time PCR, maspin mRNA was found 2-fold decreased in RA-SF compared to OASF and 70-fold in comparison to NS-SF. Using in situ hybridization, maspin mRNA was expressed in RA as well as in OA and normal synovial tissue. Whereas in normal and OA samples, expression of maspin mRNA was restricted to synovial fibroblasts in the synovial lining and sublining, in RA, maspin could additionally be observed within perivascular infiltrates in mononuclear and multinucleated cells. Importantly, maspin transcripts were also found at sites of invasion into cartilage and bone. Interestingly, on the protein level, maspin could only be detected in normal breast tissue, but neither in RA synovial tissue nor in RA or OA synovial fibroblasts.

Conclusion Since maspin is not expressed in RA-SF on the protein level, it is hypothesised that the lack of maspin could contribute to the hyperplasia of the synovial tissue in RA.

\section{THU0098 MODIFICATION OF T-LYMPHOCYTES SUBSETS IN RHEUMATHOID ARTHRITIS}

B Mioara, A Isac. Department of Rheumatology and Rehabilitation, University of Medicine and Pharmacy Timisoara Romania, Timisoara, Romania

\subsection{6/annrheumdis-2001.975}

Background The role of T-lymphocytes (LT) in the pathogenesis of rheumathoid arthritis (RA) is demonstrated, but the site of Tcell activation is still unknown. The differentiation and maturation of LT took place either in the peripheral blood (PB) and synovial fluid (SF). This process can be followed using the isoforms of the leucocyte common antigen (CD45). Cells expressing CD45RA demonstrate functional characteristics of "naive cells" and those expressing CD45RO of "memory cells". Following stimulation, naive cells lose CD45 RA and gain CD45 RO with a transitional stage of dual CD45RA and CD45RO positivity. In RA, the LT from the PB express primarily CD 45RA whereas most LT found in the SF express CD45RO. Expression of HLA-DR is increased on LT found in SF. The population of dual positive LT cells CD45RA+CD45RO+ is expanded in SF, supporting the hypothesis that the LT are activated within the joint.

Objectives Using monoclonal antibodies labelled with fluorochromes and the flow-cytometry technique we tried to evidentiate the most important modification of lymphocytes subtypes in $\mathrm{PB}$ and SF in patients with chronic arthritis.

Methods The study was performed on 29 cases: 19 with RA in the stage II and III of evolution; 8 cases with ankylosing spondylitis and 2 cases with knee ostheoarthritis used as control. Paired samples of PB and SF were obtained from all the patients. From these, nucleated cells were prepaired (after erithrocyte lysis in $\mathrm{PB}$ ) and mononuclear cells in SF after density gradient centifugation. The cells from both sources were labelled with monoclonal antibodies conjugated with fluorochromes in three colour 